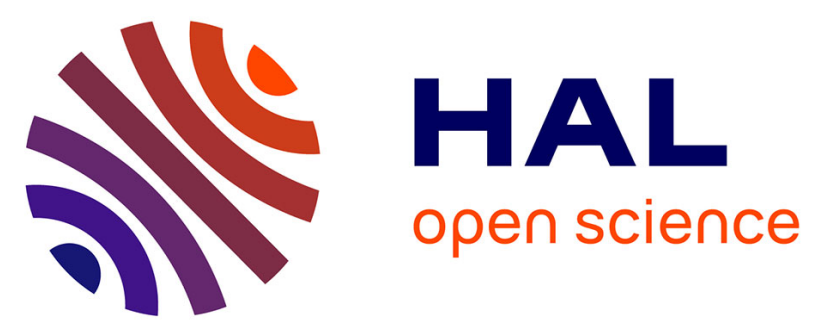

\title{
Autosomal-dominant GTPCH1-deficient DRD: clinical characteristics and long-term outcome of 34 patients
}

Iris Trender-Gerhard, Mary G Sweeney, Petra Schwingenschuh, Pablo Mir, Mark J Edwards, Alexander Gerhard, James M Polke, Mike G Hanna, Mary B Davis, Nick W Wood, et al.

\section{To cite this version:}

Iris Trender-Gerhard, Mary G Sweeney, Petra Schwingenschuh, Pablo Mir, Mark J Edwards, et al.. Autosomal-dominant GTPCH1-deficient DRD: clinical characteristics and long-term outcome of 34 patients. Journal of Neurology, Neurosurgery and Psychiatry, 2009, 80 (8), pp.839. 10.1136/jnnp.2008.155861. hal-00552711

\section{HAL Id: hal-00552711 \\ https://hal.science/hal-00552711}

Submitted on 6 Jan 2011

HAL is a multi-disciplinary open access archive for the deposit and dissemination of scientific research documents, whether they are published or not. The documents may come from teaching and research institutions in France or abroad, or from public or private research centers.
L'archive ouverte pluridisciplinaire HAL, est destinée au dépôt et à la diffusion de documents scientifiques de niveau recherche, publiés ou non, émanant des établissements d'enseignement et de recherche français ou étrangers, des laboratoires publics ou privés. 


\section{Autosomal-dominant GTPCH1-deficient DRD: clinical characteristics and long-term} outcome of 34 patients

Iris Trender-Gerhard ${ }^{1}, \mathrm{MD}$, Mary G. Sweeney ${ }^{2}, \mathrm{PhD}$, Petra Schwingenschuh ${ }^{1,3}, \mathrm{MD}$, Pablo Mir $^{1,4}$, PhD, Mark J. Edwards ${ }^{1}$, PhD, Alexander Gerhard ${ }^{5}$, PhD, James M. Polke ${ }^{2}$, PhD, Mike G. Hanna ${ }^{6}$, MD, Mary B. Davis ${ }^{2}$, PhD, Nick W. Wood ${ }^{2}$, PhD, and Kailash P. Bhatia ${ }^{1}$, MD

${ }^{1}$ Sobell Department of Motor Neuroscience and Movement Disorders, Institute of Neurology, Queen Square, London, UK; ${ }^{2}$ Department of Molecular Neuroscience, Institute of Neurology, Queen Square, London, UK; ${ }^{3}$ Department of Neurology, Medical University Graz, Austria;

${ }^{4}$ Unidad de Trastornos del Movimiento, Servicio de Neurología, Hospitales Universitarios Virgen del Rocío, CIBERNED, Seville, Spain; ${ }^{5}$ Wolfson Molecular Imaging Centre, The University of Manchester, UK; ${ }^{6} \mathrm{MRC}$ Centre for Neuromuscular Disease, Institute of Neurology, Queen Square, London, UK

\section{Address for correspondence:}

Address for Correspondence: Prof. KP Bhatia

Sobell Department

Institute of Neurology, UCL

Queen Square

London

WC1N 3BG

Tel: +44 2078373611 ext 4253

Fax: +44 2076762175

Email: k.bhatia@ion.ucl.ac.uk 
The Corresponding Author has the right to grant on behalf of all authors and does grant on behalf of all authors, an exclusive licence on a worldwide basis to the BMJ Publishing Group Ltd and its Licensees to permit this article (if accepted) to be published in the Journal of Neurology, Neurosurgery \& Psychiatry editions and any other BMJPGL products to exploit all subsidiary rights, as set in the licence (http://jnnp bmjjournals.com/ifora/licence.pdf).

Key words: Dopa-responsive dystonia, DRD, GTPCH1, treatment, pregnancy

\section{Word Count:}

Abstract: 267

Manuscript (excluding references, tables and figure legends): 3671

References: 36

Number of tables: 3 


\section{ABSTRACT}

An autosomal dominantly inherited defect in the GCH1 gene that encodes guanosine triphosphate cyclohydrolase 1 (GTPCH1) is the most common cause of dopa-responsive dystonia (DRD). A classic phenotype of young-onset lower limb dystonia, diurnal fluctuations, and excellent response to levodopa has been well recognized in association with GCH1 mutations, and rare atypical presentations have been reported. However, a number of clinical issues remain unresolved including phenotypic variability, long-term response to levodopa and associated non-motor symptoms, and there are limited data on long-term follow up of genetically proven cases. We present a detailed clinical evaluation of 34 patients (19 women, 15 men) with confirmed mutations in the GCH1 gene. We found that the classic phenotype was most frequent $(\mathrm{n}=23)$, with female predominance $(\mathrm{F}: \mathrm{M}=16: 7)$, and early onset (mean 4.5 years) with involvement of legs. However, a surprisingly large number of patients developed craniocervical dystonia, with spasmodic dysphonia being the predominant symptom in two subjects. A subset of patients, mainly men, presented with either a youngonset (mean 6.8 years) mild DRD variant not requiring treatment $(n=4)$, or with an adult-onset (mean 37 years) Parkinson's disease-like phenotype $(n=4)$. Two siblings were severely affected with early hypotonia and delay in motor development, associated with compound heterozygous GCH1 gene mutations. We also describe a number of supplementary features including restless legs-like symptoms, influence of female sex hormones, predominance of tremor or parkinsonism in adult-onset cases, initial reverse reaction to levodopa, recurrent episodes of depressive disorder, and specific levodopa-resistant symptoms (writer's cramp, dysphonia, truncal dystonia). We report that levodopa was used effectively and safely in 20 pregnancies, and did not cause any foetal abnormalities. 


\section{INTRODUCTION}

Dopa-responsive dystonia (DRD) is an uncommon but treatable movement disorder caused in about $50 \%$ of cases by an autosomal dominantly inherited defect in the gene GCH1 (14q22.1q22.2) that encodes guanosine triphosphate cyclohydrolase 1 (GTPCH1).[1, 2] So far more than 112 different mutations have been identified in GCH1.[3, 4] GTPCH1 catalyzes the ratelimiting step in tetrahydrobiopterin (BH4) biosynthesis, which itself is the essential cofactor for production of tyrosine hydroxylase (TH), tryptophan hydroxylase, and phenylalanine hydroxylase.[5] TH is the initial and rate-limiting enzyme in dopamine synthesis.[6] Patients with autosomal-dominant GTPCH1-deficient DRD are usually heterozygote for a mutation in GCH1 and therefore they have some residual GTPCH1 activity.[7]

A "classic" phenotype of DRD is recognised - onset in childhood with walking difficulties due to lower limb dystonia progressing to generalised dystonia, diurnal fluctuation of symptoms, concurrent or subsequent development of parkinsonism (mainly rigidity and bradykinesia), and an excellent and sustained response to levodopa.[8]

The classic phenotype described above seems to account for the majority of patients, but a number of cases have been reported with either an entirely different presentation or additional clinical features, such as benign adult-onset parkinsonism, DRD simulating cerebral palsy or spastic paraplegia and various types of focal dystonia.[2,9-15] This is an important issue for the clinician as DRD is both a rare disorder and also a very treatable one. Here we describe the detailed clinical findings of 34 DRD patients (2 isolated cases, 32 familial cases from 16 different families) with mutations in the GCH1 gene. In each patient, we conducted a clinical reassessment after genetic analysis with special emphasis on 4 aspects; 1) to report the frequency of "classic" versus "atypical" phenotypes in our cohort; 2) to assess the long-term 
course of symptoms and the outcome of long-term levodopa treatment; 3) to determine the frequency of less recognised motor and non-motor symptoms; 4) to address a number of clinically important issues that remain so far unresolved, such as the efficacy of dopamine agonists and controlled-release levodopa on DRD symptoms, and the management of pregnancies in affected women.

\section{METHODS}

Written informed consent for genetic and clinical investigations was obtained according to the Declaration of Helsinki and approved by the Joint Research Ethics Committee of the Institute of Neurology and the National Hospital for Neurology and Neurosurgery, London, UK.

Patients were ascertained following genetic analysis of blood samples sent to the National Hospital for Neurology and Neurosurgery where the diagnosis of DRD was suspected. DNA was extracted from EDTA blood according to standard procedures. The entire coding sequence and the exon-intron boundaries of GCH1 were screened for mutations by bidirectional sequencing. Out of a total of 42 positive patients identified by genetic screening, 34 patients could be contacted and agreed to take part in the study, hence this is not a consecutive series.

We carried out a comprehensive clinical study comprising both a retrospective analysis of medical records (age at onset, symptoms at onset, initial diagnosis, duration until final diagnosis, response to therapy, changes of therapy, symptoms and complaints throughout the disease, psychomotor development and non-motor symptoms) and a new follow up neurological assessment to ascertain any missing medical history details and to perform an 
up-to-date neurological examination of all individuals (on their usual treatment) as part of the study.

\section{RESULTS}

Thirty four subjects (18 (2 isolated, 16 familial) index patients and 16 family members) with

GCH1 mutations were investigated. The mutations, but not the detailed clinical findings, have been previously reported in nineteen of these cases.[16, 17]

\section{Mutation analysis}

Table 1: Mutations in the GCH1 gene found in the 34 DRD cases included in this study.

\begin{tabular}{|c|c|c|c|c|c|c|}
\hline \multicolumn{2}{|c|}{$\begin{array}{l}\text { Family and patient } \\
\text { number }\end{array}$} & \multirow{2}{*}{$\begin{array}{l}\text { Location } \\
\text { in gene } \\
\text { exon } 1\end{array}$} & \multirow{2}{*}{ 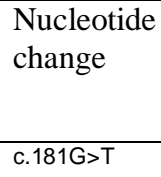 } & \multirow{2}{*}{$\begin{array}{l}\text { GCH1 mutation } \\
\text { / Predicted effect of } \\
\text { mutation } \\
\text { Glu61X }\end{array}$} & \multirow{2}{*}{$\begin{array}{l}\text { Phenotype } \\
\text { group }\end{array}$} & \multirow{2}{*}{$\begin{array}{l}\text { References } \\
{[18]}\end{array}$} \\
\hline 1.1 & familial (G2), $\mathrm{F}$ & & & & & \\
\hline 1.2 & familial (G2), M & exon 1 & c. $181 \mathrm{G}>\mathrm{T}$ & Glu61X & 1 & \\
\hline 1.3 & familial (G1), M & exon 1 & c. $181 \mathrm{G}>\mathrm{T}$ & Glu61X & 4 & \\
\hline 2.1 & familial (G3), M & exon 1 & c. $221 \mathrm{C}>\mathrm{T}$ & Ala74Val & 1 & \\
\hline 2.2 & familial (G3), F & exon 1 & c.221C>T & Ala74Val & 1 & \\
\hline 2.3 & familial (G2), $\mathrm{F}$ & exon 1 & c. $221 C>T$ & Ala74Val & 1 & [16] \\
\hline 2.4 & familial (G1), M & exon 1 & c.221C>T & Ala74Val & 2 & \\
\hline 3.1 & familial (G2), $F$ & exon 1 & c. $248 \mathrm{G}>\mathrm{C}$ & Gly83Ala & 1 & {$[15,16]$} \\
\hline 4.1 & familial (G2), F & exon 1 & c.260delA & $\begin{array}{l}\text { Gln87ArgfsX30 \& Pro23Leu } \\
\text { polymorphism }\end{array}$ & 1 & \\
\hline 4.2 & familial (G2), $F$ & exon 1 & c.260delA & Gln87ArgfsX30 & 1 & \\
\hline 4.3 & familial (G1), M & exon 1 & c.260delA & Gln87ArgfsX30 & $\begin{array}{l}\text { cannot be } \\
\text { grouped }\end{array}$ & \\
\hline 5.1 & familial (G2), M & exon 1 & c. $263 \mathrm{G}>\mathrm{C}$ & Arg88Pro & 1 & [17] \\
\hline 5.2 & familial (G1), F & exon 1 & c. $263 \mathrm{G}>\mathrm{C}$ & Arg88Pro & 2 & \\
\hline 6.1 & familial, $F$ & exon 1 & c. $272 \mathrm{~T}>\mathrm{G}$ & Leu91Arg & 1 & [19] \\
\hline 7.1 & isolated, $\mathrm{F}$ & exon 1 & c.293C>T & Ala98Val & 1 & \\
\hline 8.1 & familial, F & exon 4 & c. $510 \mathrm{G}>\mathrm{T}$ & Arg170Ser & 1 & \\
\hline 9.1 & familial (G2), $F$ & exon 5 & c. $607 \mathrm{G}>\mathrm{A}$ & Gly203Arg & 1 & {$[9,16,20]$} \\
\hline 9.2 & familial (G1), F & exon 5 & c.607G >A & Gly203Arg & 4 & \\
\hline 10.1 & isolated, $\mathrm{M}$ & exon 5 & c. $610 \mathrm{G}>\mathrm{A}$ & Val204Ile & 4 & [3] \\
\hline 11.1 & familial (G2), M & $\begin{array}{l}\text { exon } 5 \text { \& } \\
\text { exon } 2\end{array}$ & $\begin{array}{l}\text { c. } 571 \mathrm{G}>\mathrm{A}+ \\
\text { c. } 344-2 \mathrm{~A}>\mathrm{G}\end{array}$ & $\begin{array}{l}\text { Val191lle +exon } 2 \\
\text { acceptor splice site }\end{array}$ & 1 & {$[16,21]$} \\
\hline 11.2 & familial (G1), M & exon 5 & c. $571 \mathrm{G}>\mathrm{A}$ & Val191Ile & 2 & \\
\hline 12.1 & familial (G1), F & IVS 5 & c.626+2dupT & premature truncation & 1 & {$[19,22]$} \\
\hline 12.2 & familial (G1), $F$ & IVS 5 & c.626+2dupT & premature truncation & 1 & \\
\hline
\end{tabular}




\begin{tabular}{|c|c|c|c|c|c|c|}
\hline 12.3 & familial (G2), $\mathrm{F}$ & IVS 5 & c.626+2dupT & premature truncation & 1 & \\
\hline 13.1 & familial (G2), $\mathrm{F}$ & IVS 5 & c. $626+1 \mathrm{G}>\mathrm{A}$ & Splice donor site & 1 & [16] \\
\hline 14.1 & familial, F & exon 6 & c.631_632del & Met211ValfsX37 & 1 & {$[16,19]$} \\
\hline 15.1 & familial, $F$ & exon 6 & c. $646 \mathrm{C}>\mathrm{T}$ & Arg216X & 1 & {$[15,17,19]$} \\
\hline 15.2 & familial, M & exon 6 & c. $646 \mathrm{C}>\mathrm{T}$ & Arg216X & 2 & \\
\hline 16.1 & familial (G2), M & exon 6 & c. $670 \mathrm{~A}>\mathrm{T}$ & Lys224X & 1 & {$[16,23]$} \\
\hline 16.2 & familial (G2), M & exon 6 & c. $670 \mathrm{~A}>\mathrm{T}$ & Lys224X & 1 & \\
\hline 16.3 & familial (G1), M & exon 6 & c. $670 \mathrm{~A}>\mathrm{T}$ & Lys224X & 4 & \\
\hline 17.1 & familial, M & exon 6 & c. $670 \mathrm{~A}>\mathrm{T}$ & Lys224X & 1 & \\
\hline 18.1 & familial (G2), M & $\begin{array}{l}\text { exon } 6 \\
\text { intron } 1\end{array}$ & $\begin{array}{l}\text { c. } 671 \mathrm{~A}>\mathrm{G} \\
\text { c. } 343+5 \mathrm{G}>\mathrm{C}\end{array}$ & $\begin{array}{l}\text { Lys224Arg } \\
\text { p.(?) }\end{array}$ & 3 & {$[14,17,24,25]$} \\
\hline 18.2 & familial (G2), $\mathrm{F}$ & $\begin{array}{l}\text { exon } 6 \\
\text { intron } 1\end{array}$ & $\begin{array}{l}\text { c. } 671 A>G \\
\text { c. } 343+5 G>C\end{array}$ & $\begin{array}{l}\text { Lys224Arg } \\
\text { p.(?) }\end{array}$ & 3 & \\
\hline
\end{tabular}

Legend: G (generation), G1 (oldest generation), G2 and G3 (younger generations), M (male), F (female), Phenotype group (1: Young-onset classic; 2: Young-onset mild; 3: Young-onset severe with initial hypotonia; 4: Adult-onset)

19 mutations in GCH1 were detected. Four mutations were new (c.260delA, p.Gln87ArgfsX30 in exon 1; c.293C>T, p.Ala98Val in exon 1; c.510G>T, p.Arg170Ser in exon 4 ; c.343+5G >C, p.(?) in intron 1), and fifteen mutations have been described previously. Of mutations that have been described previously, one (c.670A>T; p.Lys224X in exon 6) was detected in 2 apparently unrelated index patients (16.1 and 17.1).

One index patient (11.1) had 2 mutations in GCH1 (Val191Ile in exon5 and c.344-2A>G p.(?) in intron 1). The Val191Ile mutation was present in his father (11.2) but his mother did not have either mutation, suggesting that the c.344-2A>G arose de novo in this individual. The phase of these mutations is unknown.

Two siblings (18.1 and 18.2) with initial hypotonia followed by the most severe phenotype of DRD with marked delay in motor development have been reported previously showing the Lys224Arg mutation.[17, 24] We now report that both patients are compound heterozygotes 
for GCH1 mutations. In addition to the Lys224Arg mutation (inherited from their father) we discovered a novel mutation inherited from their mother (c.343+5G $>$ C; p.(?)). Both parents were clinically asymptomatic.

\section{Clinical findings}

The clinical characteristics of our 34 patients are summarized in table 2 . The mean age of patients at the time of the study was 42.4 years (range: $14-82$ years). The mean duration of disease was 33.2 years (range: 4-76 years). The female: male ratio was 1.3:1 in the whole cohort.

Table 2: Summary of the clinical characteristics of our 34 patients with DRD due to a GTPCH1 mutation (1 male patient could not state age of onset and initial symptoms)

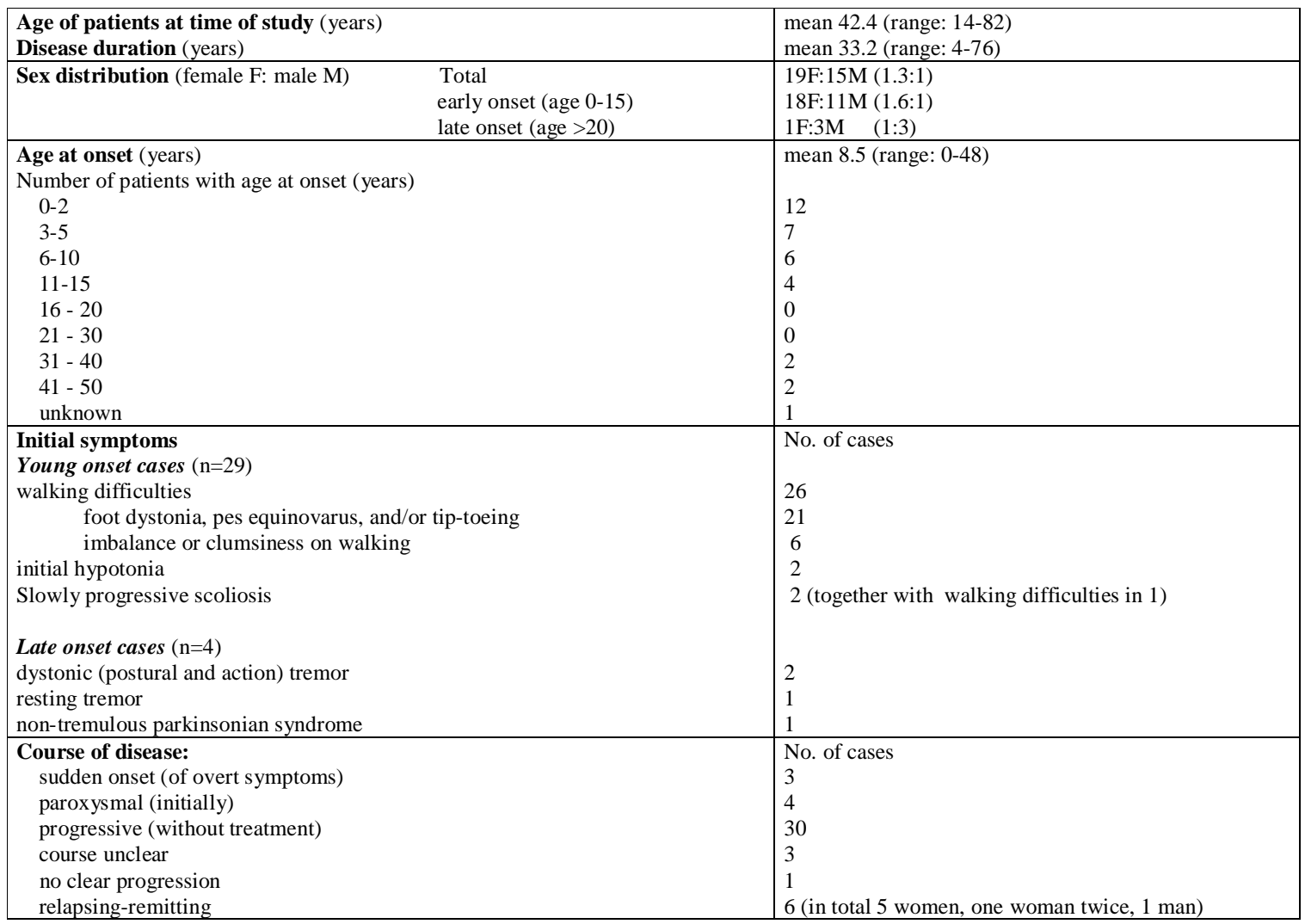




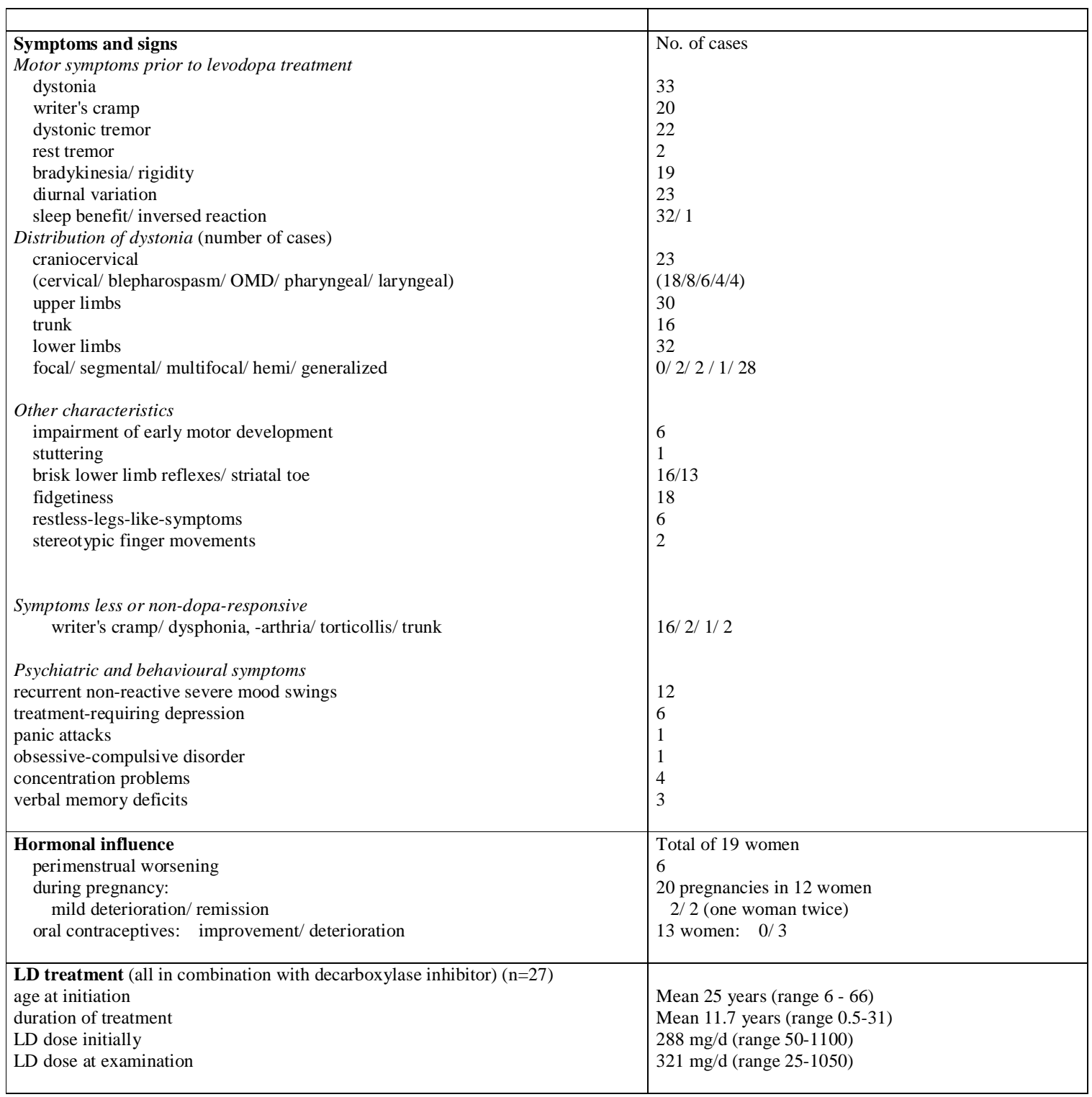

\section{Age at onset}

The reported age at onset varied between 0 and 48 years (mean 8.5 years). Onset occurred slightly (not significantly) earlier in women (mean $7.4 \pm 10.6$ years) than in men (mean $9.9 \pm 13.4$ years). In 29 patients $(85 \%)$ the illness started before the age of 15 (in this article referred to as young-onset cases), and in 12 of these patients (35\%) even within the first 18 months of life. Only 4 patients ( 3 men, 1 woman) had their disease onset in adulthood at a 
mean age of 37 years. Below we refer to these 4 patients as "adult-onset cases". One subject could neither state age at onset nor initial symptoms.

\section{Presenting symptoms}

In most young-onset cases (90\%), symptoms started gradually with walking difficulties, typically due to unilateral or bilateral foot dystonia. Five patients presented with paroxysmal exercise-induced lower limb dystonia progressing to persistent symptoms in three of them. In two siblings the disease started with initial truncal hypotonia and another patient presented with feeding problems after birth. Slowly progressive scoliosis in childhood was the first symptom in one man. Interestingly, in three out of four adult-onset cases upper limb tremor was the initial presentation (either a postural/action tremor or a rest tremor). The other adultonset patient presented initially with a non-tremulous parkinsonian syndrome.

\section{Progression of symptoms prior to levodopa therapy}

Dystonia affected the legs in $94 \%$, with upper limbs also involved in $88 \%$ (in the majority the dominant upper limb feature was focal hand dystonia). Truncal dystonia was observed in $47 \%$. In $68 \%$ either the cranial and/or cervical region was involved, with cervical dystonia in 18 , blepharospasm in 8 , oromandibular dystonia in 6 and spasmodic dysphonia in 4 subjects. Severe spasmodic dysphonia was the predominant feature in two patients. In nineteen patients bradykinesia and/or rigidity was also noted. Despite longstanding illness and increasing age, the severity of the parkinsonian component in early-onset cases never exceeded the dystonic one.

$65 \%$ of patients developed limb tremor. It occurred on posture and/or action and was usually confined to the arms. Tremor affecting the voice, head and chin were also seen in one patient 
each. Tremor was the initial and remained the most prominent clinical feature in 3 out of the 4 individuals with onset in adulthood. Two of these cases had a tremor at rest.

18 out of 34 subjects complained of feeling fidgety, often present since childhood. Such restlessness clearly started prior to levodopa treatment in at least 6 cases. These symptoms resembled those of restless legs syndrome, with a need to move the legs associated in some with uncomfortable sensations in the legs, worsening at rest or with diminished activity, and improving with movement. However, only 4/18 patients noted a clear worsening in the evening and at night and therefore met the restless legs syndrome diagnostic criteria.[26] In 4 patients their daytime restless legs like symptoms improved substantially with levodopa. Pseudo-pyramidal features such as brisk lower limb reflexes or extensor plantars ("striatal toes") were present in 16 and 13 patients, respectively.

In 23 out of 29 young-onset cases symptoms showed moderate to severe progression (in both symptom severity and spread of symptoms to previously unaffected body parts) within the first few years of disease followed by a slower deterioration. Spontaneous remissions occurred in six patients ( 5 women, 1 man) between age 3 and 30 years. All relapsed after 2 to 3 years. In $70 \%$ of patients symptoms clearly worsened towards the end of the day. $70 \%$ of patients also noted exercise-related worsening of symptoms.

Patients were clinically diagnosed with probable DRD on average 20.7 years (range 1-58 years) after disease onset. The most common misdiagnoses were cerebral palsy $(n=6)$, idiopathic torsion dystonia (5), hereditary spastic paraplegia (2), and Parkinson's disease (2). 


\section{Psychiatric and Behavioural Symptoms}

In more than half of the cases a variety of psychiatric and/or neuropsychological disorders was noted either on examination or from their medical records. The assessment of these symptoms was not performed in a standardised fashion, so these data are by their nature descriptive. The most common reported symptoms were severe mood swings $(n=12)$ and treatment-requiring depression $(n=6)$. One patient was suicidal in his late teens. One patient each was additionally diagnosed with panic attacks and obsessive-compulsive disorder. Many individuals could not state the onset of the psychiatric symptoms, but in at least 6 patients the symptoms pre-dated dopaminergic treatment.

\section{Influence of hormonal changes}

Before initiation of dopaminergic therapy one third of our female patients experienced premenstrual or menstrual aggravation of symptoms. These monthly fluctuations were alleviated by levodopa. Three of the 13 women taking oral contraceptives reported moderate to marked worsening of symptoms while on this medication. Out of a total of 20 pregnancies that occurred in 12 of our patients (all were on levodopa therapy), 2 women reported mild deterioration of dystonia during their only pregnancy (with an increase in dose required in one). Two other women experienced a marked remission (one of them in both her pregnancies) allowing reduction or cessation of levodopa therapy during pregnancy and for some months beyond. No foetal or developmental abnormalities were reported following these pregnancies.

\section{Treatment}

In all the 27 patients requiring treatment, levodopa in combination with a decarboxylase inhibitor (DCI) was the initial dopaminergic drug. All but one patient required less than $600 \mathrm{mg} / \mathrm{d}$, with some patients having excellent response at less than $100 \mathrm{mg} / \mathrm{d}$. Immediate 
response was noted in all, even in longstanding severely disabled cases. The older of the two most severely affected siblings continued to improve over the first two years of treatment. All other patients achieved their maximum response, which was marked to excellent, within 2-3 months after levodopa initiation.

Nine patients remained on a stable dose of levodopa from treatment onset. However, the dose required increased in 9 patients, and 9 patients were switched to a controlled-release preparation. After a mean treatment time of 11.7 years (0.5-31 years) the dose of levodopa was on average $321 \mathrm{mg} /$ day (range $25-1050 \mathrm{mg} /$ day). Although the maximum benefit since levodopa initiation was usually sustained, mild progression of dystonia was seen in 6 patients despite treatment adjustment.

Side effects during the initial phase of levodopa treatment were mild to marked chorea $(n=8)$, nausea $(n=6)$, headache $(n=2)$, fatigue $(n=1)$ and temporary worsening of dystonia or postural tremor $(n=4)$. One patient continued to have mild chorea and agitation half an hour after intake of $25 \mathrm{mg}$ levodopa in the morning, and another patient reported severe levodopa induced mood swings. None of the patients developed long-term levodopa side effects typically seen in the treatment of Parkinson's disease such as motor fluctuations or disabling dyskinesias.

Despite dramatic overall benefit from levodopa some dystonic symptoms responded less well than others. Only 2 out of 18 treated patients with writer's cramp had full resolution of symptoms. Spasmodic dysphonia in two patients also showed insufficient levodopa response.

Cabergoline was added to levodopa in 4 subjects, but was withdrawn in 3 of them because of side effects or insufficient response. The remaining patient withdrew her levodopa, and 
remained on $1 \mathrm{mg}$ cabergoline daily as monotherapy, which remarkably improved her involuntary jerks, her restless-legs-like symptoms and her levodopa induced mood swings. Combining levodopa with ropinirole led to further improvement in one severely disabled individual. Anticholinergics such as trihexiphenidyl or methixene were used in small doses in five patients prior to levodopa treatment. They had a moderate $(n=3)$ to excellent $(n=2)$ effect on all symptoms, particularly on tremor.

\section{Long-term functional outcome}

After a mean disease duration of 32.7 years (range: $4-76$ years), ten patients rated themselves to be virtually asymptomatic with treatment. Thirteen patients rated themselves to be mildly affected by dystonia. Four patients reported having continuous or occasional moderate symptoms especially when missing a dose of levodopa, when being tired or after heavy exercise. Only one patient (18.2) had a clear but incomplete response to levodopa and remained markedly disabled, unable to walk independently.

\section{DISCUSSION}

\section{Main phenotypes}

In this study we report on the largest cohort of patients with autosomal-dominant GTPCH1deficient DRD to date. Within this cohort, we have distinguished 4 phenotypic groups based on age at onset, predominance of dystonia versus tremor and parkinsonism, progression of disease and longterm outcome (see table 3). 
Table 3: Four main groups of phenotypes according to age at onset, initial symptoms, natural course of disease prior to treatment, and response to levodopa $(n=33 ; 1$ patient could not state age at onset or initial symptoms)

\begin{tabular}{|c|c|c|c|c|}
\hline Phenotypes & $\begin{array}{l}\text { Young-onset } \\
\text { classic }\end{array}$ & $\begin{array}{l}\text { Young-onset } \\
\text { mild }\end{array}$ & $\begin{array}{l}\text { Young-onset } \\
\text { severe with initial } \\
\text { hypotonia }\end{array}$ & Adult-onset \\
\hline Number & 23 & 4 & 2 (siblings) & 4 \\
\hline F:M & $16: 7(2.3: 1)$ & $1: 3$ & $1: 1$ & $1: 3$ \\
\hline $\begin{array}{l}\text { Mean age at onset } \\
( \pm \text { SD; range) } \\
\text { (range) in years }\end{array}$ & $4.5( \pm 4.6 ; 1-15)$ & $7.3( \pm 3.9 ; 5-13)$ & $0.3( \pm 0.3 ; 0.1-0.5)$ & $37.0( \pm 8.2 ; 30-48)$ \\
\hline $\begin{array}{l}\text { Mean duration of } \\
\text { follow-up }( \pm S D) \text { in } \\
\text { years }\end{array}$ & $37.7( \pm 17.9)$ & $59.5( \pm 13.4)$ & $23.0( \pm 7.1)$ & $19.8( \pm 12.9)$ \\
\hline Initial symptoms & $\begin{array}{l}\text { Onset with } \\
\text { walking } \\
\text { difficulties }\end{array}$ & $\begin{array}{l}\text { Onset with } \\
\text { episodic foot } \\
\text { dystonia, toe } \\
\text { walking or } \\
\text { progressive } \\
\text { scoliosis }\end{array}$ & $\begin{array}{l}\text { Hypotonia in the } \\
\text { first year of life }\end{array}$ & $\begin{array}{l}\text { Onset with } \\
\text { dystonic and/or } \\
\text { resting tremor or } \\
\text { mild atremulous } \\
\text { parkinsonism }\end{array}$ \\
\hline $\begin{array}{l}\text { Disease course } \\
\text { (prior to treatment) }\end{array}$ & $\begin{array}{l}\text { Slowly progressive } \\
\text { dystonia, } \\
\text { generalising/ } \\
\text { increasing in } \\
\text { severity over the } \\
\text { next } 10-20 \text { years, } \\
\text { subsequently } \\
\text { development of } \\
\text { dystonic tremor } \\
\text { and mild } \\
\text { parkinsonism, } \\
\text { diurnal fluctuation }\end{array}$ & $\begin{array}{l}\text { Very mild } \\
\text { symptoms } \\
\text { throughout disease }\end{array}$ & $\begin{array}{l}\text { Followed by } \\
\text { severe delay in } \\
\text { motor } \\
\text { development, and } \\
\text { rapid progression } \\
\text { of severe } \\
\text { generalised } \\
\text { dystonia and } \\
\text { pronounced } \\
\text { involvement of the } \\
\text { oropharyngeal } \\
\text { region }\end{array}$ & $\begin{array}{l}\text { Symptoms } \\
\text { remaining mild }\end{array}$ \\
\hline Treatment & $\begin{array}{l}\text { Excellent response } \\
\text { to levodopa }\end{array}$ & No therapy needed & $\begin{array}{l}\text { Resolving } \\
\text { symptoms with } \\
\text { levodopa in one, } \\
\text { only partial } \\
\text { improvement in } \\
\text { the other sibling }\end{array}$ & $\begin{array}{l}\text { Treatment required } \\
\text { due to tremor only } \\
\text { in 50\%, excellent } \\
\text { response to } \\
\text { levodopa }\end{array}$ \\
\hline
\end{tabular}

The overwhelming majority of individuals $(\mathrm{n}=23)$ presented with a young-onset classic phenotype, with excellent response to levodopa, as first characterized by Segawa.[8] The natural history was of onset of symptoms in childhood with gait disturbance due to dystonic posturing of the legs, diurnal fluctuation, progressive course in the first several years leading to generalisation of dystonia with lower limb predominance, later plateau of symptoms, and 
development of postural arm tremor and parkinsonism. The age of onset of our classic cases varied between the first year of life and age fifteen and therefore resembled the age at onset in a series $(n=28)$ of GTPCH1-deficient DRD reported by Segawa et al. (from 16 months to 13 years).[2] The distribution of dystonia in our series however differs somewhat with $66 \%$ of our patients developing craniocervical dystonia during the disease course, as opposed to only $11 \%$ in the series by Segawa et al.[2] Two of our patients even had spasmodic dysphonia as dominant symptom persisting despite levodopa treatment. Females are relatively overrepresented in this group $(2.3: 1)$.

A second group of patients $(\mathrm{n}=4)$ have a young-onset "mild" phenotype with symptoms that start in childhood, but in contrast to the "classic" phenotype, remain very mild and often do not require treatment. These symptoms are predominantly of dystonia affecting the legs, but with little symptom progression and therefore little functional disability. Males are relatively over-represented in this group (3:1).

The third group (young-onset severe phenotype) comprised two siblings who presented with truncal hypotonia in the first year of life, followed by significant delay in motor development, and rapid progression of severe generalised dystonia with pronounced involvement of the oropharyngeal region, and normal intellectual function. They had normal plasma phenylalanine concentrations. The older sibling only received levodopa treatment from age 18 when her motor symptoms were already complicated by marked contractures and skeletal deformities. She had marked benefit but never regained a normal state, while the younger brother virtually recovered after levodopa introduction at age 6 . Both siblings revealed compound heterozygosity with maternally and paternally transmitted GCH1 gene mutations. Lys224Arg had been found in one compound heterozygote (additional Gly108Asp mutation) reported by Furukawa presenting with the same disabling type of DRD with marked 
developmental delay.[14] This phenotype in compound heterozygotes for significant GCH1 mutations is clinically and biochemically intermediate between autosomal-dominant GTPCH1-deficient DRD (heterozygotes) and autosomal-recessive GTPCH1-deficiency (usually homozygotes) who develop BH4-dependent hyperphenylalaninemia in the first 6 months of life.[27] A similar phenotype may occur in patients with the severe form of THdeficiency.[27]

A fourth group in our cohort $(\mathrm{n}=4)$ has an adult-onset mild phenotype. This group comprises adult-onset patients, with either upper limb tremor or atremulous parkinsonism as the initial complaint usually accompanied by mild dystonic features, lack of diurnal fluctuation, and very slow disease progression. These patients may be difficult to distinguish from youngonset Parkinson's disease. Males are again over-represented in this group (3:1). Three of these parkinsonian patients were screened for a mutation in the GCH1 gene as they had relatives with clinically typical DRD. One patient developed resting, postural and action tremor of upper limbs at age 30, later progressing to both his legs, with reduced arm swing, hypomimia and slowness on repetitive finger tasks, was diagnosed with young-onset Parkinson's disease in his late 40s. His response to levodopa was excellent and symptoms did not progress any further. At age 52 an F-dopa PET scan was reported to be normal and therefore a gene test was requested that revealed a mutation in the $\mathrm{GCH} 1$ gene.

This analysis suggests that females exhibit classic DRD symptoms more frequently and earlier in life than men which, in turn, is related to a higher degree of disability. In contrast, males appear to be more likely to have a milder phenotype or later disease onset. We suspect that this might artificially increase the female predominance among DRD patients, since male patients may be more likely to be misdiagnosed as young-onset Parkinson's disease or do not come to medical attention due to mild disease severity. We also found in some families a 
tendency for younger generations to be more severely affected than older generations although having the same mutations. This may be due to ascertainment bias or to genetic anticipation.

The female predominance in young-onset disease may reflect a higher vulnerability of the dopaminergic system to BH4 deficiency in females, particularly in early development. One possible component of this vulnerability in females may be the regulatory effect of oestrogen on GTPCH1 expression.[28] There may well be other differences in GTPCH1 activity,[1] GCH1 mRNA expression levels or TH levels that also contribute to gender-related differences in symptom severity.[1,29] These factors may underlie the association between female sex and age at onset, severity of symptoms, as well as the findings in our cohort of the effect of the contraceptive pill, menstruation, and pregnancy on symptoms. Menstruation-related worsening or marked exacerbation on oral contraceptives in genetically proven DRD cases have been described only occasionally.[14, 30-32] In contrast, a quarter of our female subjects experienced pre-/menstrual aggravation of symptoms, and oral contraceptives caused distinct worsening in 3 out of 13 women.

\section{DRD and pregnancy}

Our study is the first to report on a large number of pregnancies $(n=20)$ in genetically proven DRD cases. Remissions occurred in 3 pregnancies, whereas mild temporary deterioration was described twice in our study and required a dose adjustment of levodopa in one woman. In the majority of pregnancies reported here levodopa could be continued at a stable dose during the pregnancy, and no foetal abnormalities were reported. 


\section{Psychiatric comorbidity}

So far, clinical features possibly related to tryptophan hydroxylase hypoactivity and serotonergic dysfunction have generally not been reported to be relevant in DRD.[33] Only recently has attention been drawn to an increased frequency of psychiatric dysfunctions including major depressive disorders, anxiety, and obsessive-compulsive disorder in a cohort of 18 subjects with GTPCH1 deficiency and reduced 5-HIAA and 3-methoxy-4hydroxyphenylglycol CSF levels have been shown.[34]

We collected our data regarding psychiatric abnormalities from patients' medical records and no formal neuropsychiatric assessment was obtained as part of the study. However, the high incidence of documented neuropsychological abnormalities among our DRD cases was striking. These often antedated the initiation of levodopa or recurred despite efficient and stable treatment with levodopa. The frequency of recurrent episodes of depressive disorders, either non-reactive mood swings (12/34) or major depression (6/34), was significantly increased compared to the population incidence.[35] Additional features such as panic attacks, obsessive-compulsive disorder, concentration problems and verbal memory deficits were noted in several individuals. Psychiatric symptoms were not reported to precede motor signs in any of our patients.

\section{Treatment}

The majority of our patients was managed throughout the disease with a total levodopa (plus DCI) of less than $600 \mathrm{mg} /$ day, with some patients having sustained excellent response at less than $100 \mathrm{mg} /$ day. Previous reports had suggested that maximum benefit in DRD is usually achieved by less than $20 \mathrm{mg} / \mathrm{kg} /$ day of plain levodopa (without a DCI)[2] or by less than 300mg/day of levodopa (with a DCI),[36] while some adult patients with GCH1 mutations needed 400mg/day of levodopa in combination with a DCI.[22] The effects of dopamine 
agonists and controlled-release preparations of levodopa in DRD have so far been unclear. No clinical trials comparing them with standard levodopa have been performed. This study provides some uncontrolled observations that these drugs can be used successfully in DRD. The vast majority of our patients were well controlled on standard levodopa in the long-term, but there was a small number of patients in our cohort who found switching from standard levodopa to controlled release levodopa or a dopamine agonist to be of benefit. In our patients, the reasons for switching from standard levodopa included mild levodopa induced dyskinesia, mood swings, insufficient response with re-emergence of diurnal fluctuations, difficulties with compliance and restless legs-like symptoms.

\section{CONCLUSION}

Our results demonstrate that the majority of patients with GCH1 mutations will fit into the "classic" phenotype described by Segawa. However, the clinician should be aware of the possibility of both young presentation with very minor motor symptoms, or adult presentation (particularly in males) with symptoms and signs resembling young-onset Parkinson's disease which led to misdiagnosis in our cohort. Our data underline that the overall long-term responsiveness to levodopa in these patients is excellent. Increased doses of levodopa are only required in a minority even after many years of treatment. Chronic side effects such as dyskinesias or motor fluctuations are unlikely to occur.

Based on the twenty pregnancies reported here, our data suggest that levodopa retains efficacy during pregnancy and was not associated with any foetal abnormalities. We have also found that controlled release levodopa or dopamine agonists can be useful in rare cases either in isolation or as adjuvant therapy. Clinical features such as writer's cramp and laryngeal dystonia were insufficiently controlled in many patients despite levodopa treatment, and for 
these symptoms additional treatment options such as botulinum toxin might be required. Despite adequate treatment of motor symptoms, psychiatric problems were frequent in our cohort. Further structured assessment of the nature of these symptoms and how they add to the clinical burden of DRD is needed so that appropriate assessment and treatment guidelines can be developed.

\section{Acknowledgments: none}

Competing interests: none

Funding: none

\section{References}

1. Ichinose $\mathrm{H}$, Ohye $\mathrm{T}$, Takahashi E, et al. Hereditary progressive dystonia with marked diurnal fluctuation caused by mutations in the GTP cyclohydrolase I gene. Nat Genet 1994;8(3):236-42.

2. Segawa M, Nomura Y, Nishiyama N. Autosomal dominant guanosine triphosphate cyclohydrolase I deficiency (Segawa disease). Ann Neurol 2003;54 Suppl 6:S32-45.

3. Furukawa Y. Genetics and biochemistry of dopa-responsive dystonia: significance of striatal tyrosine hydroxylase protein loss. Adv Neurol 2003;91:401-10.

4. Blau N, Thoeny B, Dianzani I. Database of mutations causing tetrahydrobiopterin deficiencies. [date accessed June 2008; http://www.bh4.org/BH4Databases.asp].

5. Kaufman S. Studies on the mechanism of the enzymatic conversion of phenylalanine to tyrosine. J Biol Chem 1959;234:2677-82.

6. Nagatsu T, Levitt M, Udenfriend S. Tyrosine Hydroxylase. The Initial Step In Norepinephrine Biosynthesis. J Biol Chem 1964;239:2910-7. 
7. Ichinose H, Ohye T, Matsuda Y, et al. Characterization of mouse and human GTP cyclohydrolase I genes. Mutations in patients with GTP cyclohydrolase I deficiency. J Biol Chem 1995;270(17):10062-71.

8. Segawa M, Ohmi K, Itoh S, et al. Childhood basal ganglia disease with remarkable response to L-Dopa, hereditary basal ganglia disease with marked diurnal fluctuation. Shinryo 1971;24:667-672.

9. Kong $\mathrm{CK}$, Ko CH, Tong SF, et al. Atypical presentation of dopa-responsive dystonia: generalized hypotonia and proximal weakness. Neurology 2001;57(6):1121-4.

10. Regula JU, Thoden U, Meinck HM. Adult-onset dystonia: Atypical manifestation of Segawa disease. Mov Disord 2007;22(9):1335-7.

11. Furuya H, Murai H, Takasugi K, et al. A case of late-onset Segawa syndrome (autosomal dominant dopa-responsive dystonia) with a novel mutation of the GTPcyclohydrase I (GCH1) gene. Clin Neurol Neurosurg 2006;108(8):784-6.

12. Chaila EC, McCabe DJ, Delanty N, et al. Broadening the phenotype of childhoodonset dopa-responsive dystonia. Arch Neurol 2006;63(8):1185-8.

13. Hjermind LE, Johannsen LG, Blau N, et al. Dopa-responsive dystonia and early-onset Parkinson's disease in a patient with GTP cyclohydrolase I deficiency? Mov Disord 2006;21(5):679-82.

14. Furukawa Y, Kish SJ, Bebin EM, et al. Dystonia with motor delay in compound heterozygotes for GTP-cyclohydrolase I gene mutations. Ann Neurol 1998;44(1):10-6.

15. Tassin J, Durr A, Bonnet AM, et al. Levodopa-responsive dystonia. GTP cyclohydrolase I or parkin mutations? Brain 2000;123(Pt 6):1112-21.

16. Bandmann O, Valente EM, Holmans P, et al. Dopa-responsive dystonia: a clinical and molecular genetic study. Ann Neurol 1998;44(4):649-56. 
17. Bandmann O, Nygaard TG, Surtees R, et al. Dopa-responsive dystonia in British patients: new mutations of the GTP-cyclohydrolase I gene and evidence for genetic heterogeneity. Hum Mol Genet 1996;5(3):403-6.

18. Nitschke M, Steinberger D, Heberlein I, et al. Dopa responsive dystonia with Turner's syndrome: clinical, genetic, and neuropsychological studies in a family with a new mutation in the GTP-cyclohydrolase I gene. J Neurol Neurosurg Psychiatry 1998;64(6):806-8.

19. Hagenah J, Saunders-Pullman R, Hedrich K, et al. High mutation rate in doparesponsive dystonia: detection with comprehensive GCHI screening. Neurology 2005;64(5):908-11.

20. Skrygan M, Bartholome B, Bonafe L, et al. A splice mutation in the GTP cyclohydrolase I gene causes dopa-responsive dystonia by exon skipping. J Inherit Metab Dis 2001;24(3):345-51.

21. Weber Y, Steinberger D, Deuschl G, et al. Two previously unrecognized splicing mutations of GCH1 in Dopa-responsive dystonia: exon skipping and one base insertion. Neurogenetics 1997;1(2):125-7.

22. Steinberger D, Korinthenberg R, Topka H, et al. Dopa-responsive dystonia: mutation analysis of GCH1 and analysis of therapeutic doses of L-dopa. German Dystonia Study Group. Neurology 2000;55(11):1735-7.

23. Ludecke B, Dworniczak B, Bartholome K. A point mutation in the tyrosine hydroxylase gene associated with Segawa's syndrome. Hum Genet 1995;95(1):123-5.

24. Robinson R, McCarthy GT, Bandmann O, et al. GTP cyclohydrolase deficiency; intrafamilial variation in clinical phenotype, including levodopa responsiveness. J Neurol Neurosurg Psychiatry 1999;66(1):86-9.

25. Leuzzi V, Carducci C, Carducci C, et al. Autosomal dominant GTP-CH deficiency presenting as a dopa-responsive myoclonus-dystonia syndrome. Neurology 2002;59(8):12413. 
26. Allen RP, Picchietti D, Hening WA, et al. Restless legs syndrome: diagnostic criteria, special considerations, and epidemiology. A report from the restless legs syndrome diagnosis and epidemiology workshop at the National Institutes of Health. Sleep Med 2003;4(2):101-19. 27. Furukawa Y. Update on dopa-responsive dystonia: locus heterogeneity and biochemical features. Adv Neurol 2004;94:127-38.

28. Serova LI, Filipenko M, Schilt N, et al. Estrogen-triggered activation of GTP cyclohydrolase 1 gene expression: role of estrogen receptor subtypes and interaction with cyclic AMP. Neuroscience 2006;140(4):1253-63.

29. Shimoji M, Hirayama K, Hyland K, et al. GTP cyclohydrolase I gene expression in the brains of male and female hph-1 mice. J Neurochem 1999;72(2):757-64.

30. Nygaard TG, Takahashi H, Heiman GA, et al. Long-term treatment response and fluorodopa positron emission tomographic scanning of parkinsonism in a family with doparesponsive dystonia. Ann Neurol 1992;32(5):603-8.

31. Nomura Y, Uetake K, Yukishita S, et al. Dystonias responding to levodopa and failure in biopterin metabolism. Adv Neurol 1998;78:253-66.

32. Fink JK, Ravin PD, Filling-Katz M, et al. Clinical and genetic analysis of progressive dystonia with diurnal variation. Arch Neurol 1991;48(9):908-11.

33. Furukawa Y, Kish SJ. Dopa-responsive dystonia: recent advances and remaining issues to be addressed. Mov Disord 1999;14(5):709-15.

34. Van Hove JL, Steyaert J, Matthijs G, et al. Expanded motor and psychiatric phenotype in autosomal dominant Segawa syndrome due to GTP cyclohydrolase deficiency. J Neurol Neurosurg Psychiatry 2006;77(1):18-23.

35. Narrow WE, Rae DS, Robins LN, et al. Revised prevalence estimates of mental disorders in the United States: using a clinical significance criterion to reconcile 2 surveys' estimates. Arch Gen Psychiatry 2002;59(2):115-23. 
36. Nygaard T, Snow BJ, Fahn S. Dopa-responsive dystonia: clinical characteristics and definition. In: Segawa M, ed. Hereditary progressive dystonia with marked diurnal fluctuation. New York: Parthenon 1993:21-35.

\section{Appendices: none}

